\title{
Heart disease in pregnancy-clinical pattern and prevalence: initial data from the first cardio-maternal unit in Iraq
}

\author{
Hasan Ali Farhan ${ }^{1,2^{*}}$ (1) and Israa Fadhil Yaseen ${ }^{2}$
}

\begin{abstract}
Objectives: The purpose of this study to determine the clinical pattern and prevalence of heart disease in pregnancy at the first established cardio-maternal unit in Iraq over the last 4 years; since January 2015 till May 2019. Data are presented as number and percentage.

Results: A total of 252 pregnant women presented to cardio-maternal unit included in this study. According to the collected data, among the main diagnosis of heart disease during pregnancy was valvular heart disease $34.1 \%$, followed by congenital heart disease 30.5\%, cardiomyopathy 29.8\%, pulmonary hypertension 4\%, and ischemic heart disease $1.6 \%$. Among subtypes of the main heart diseases in pregnant women, the most clinical pattern was: the prosthetic heart valve (26.7\%) in valvular heart disease, both atrial septal defect and ventricular septal defect (35\%) in congenital heart disease, and peripartum cardiomyopathy (76\%) among cardiomyopathies.
\end{abstract}

Keywords: Pregnancy, Heart disease, Clinical pattern, Prevalence

\section{Introduction}

Cardiovascular disease (CVD) in women is associated with $4 \%$ complications during their pregnancy and is the most frequent leading cause of maternal mortality reaching up to $15 \%$ [1-4]. After 2010, the rate of maternal mortality mainly in emerging countries began to decline, despite increasing numbers of high-risk patients [2]. This decline may be related to improvement in medical service; which generally includes cardiologist, obstetrician, and anesthetist, following European Society of Cardiology guidelines for management of CVD during pregnancy, and registration of patients' data which is improving significantly in the emerging countries as it was shown while comparing data from PREG1 and PREG2 cohorts (21.3\% vs 45.3\%); PREG1 and PREG2 cohort data were collected from the main international "Registry Of Pregnancy And Cardiac disease" which was established by the EURObservational Research Programme of the European

\footnotetext{
*Correspondence: al_farhan2004@yahoo.com

1 Scientific Council of Cardiology, Iraqi Board for Medical Specializations, Baghdad, Iraq

Full list of author information is available at the end of the article
}

Society of Cardiology to include large number of pregnant women with CVD from the real world daily practice to identify the outcomes of these patients and in order to improve their outcomes as an ultimate goal $[2,5,6]$. Cardiovascular registries have an essential role in the prevention, diagnosis and treatment of CVD in the real world practice consequently, provide an evidence based of the clinically important outcomes and they are a key tool for enhancing and raising the standard of the health and patients care [7, 8]. In this article, we will demonstrate for the first time the clinical pattern and prevalence of heart disease (HD) in pregnant women presented to the first established cardio-maternal unit in Iraq over 4 years, this will encourage to spread the registration nationally and internationally leading to improve prevention, diagnosis and management of HD during pregnancy.

\section{Main text \\ Methods}

A total of 252 pregnant women with heart disease who presented to cardio-maternal unit/Baghdad Heart Center/Baghdad Teaching Hospital/Medical City between January 2015 and May 2019 were included in 
this study. Patients were referred to cardio-maternal unit either with a known case of heart disease or with symptoms requiring cardiac investigation (electrocardiogram

\section{Table 1 Clinical pattern and prevalence of heart disease} in pregnancy at cardio-maternal clinic

\begin{tabular}{|c|c|c|c|}
\hline Main diagnosis & Total no. (\%) & Subtypes & Subtypes no. (\%) \\
\hline \multirow[t]{6}{*}{ VHD } & $86(34.1 \%)$ & PHV & $23(26.7 \%)$ \\
\hline & & MS & $22(25.6 \%)$ \\
\hline & & MR & 18 (20.9\%) \\
\hline & & PS & $11(12.8 \%)$ \\
\hline & & AR & $8(9.3 \%)$ \\
\hline & & AS & $4(4.7 \%)$ \\
\hline \multirow[t]{5}{*}{$\mathrm{CHD}$} & 77 (30.5\%) & ASD & 27 (35\%) \\
\hline & & VSD & 27 (35\%) \\
\hline & & TOF & $8(10.4 \%)$ \\
\hline & & Miscellaneous & $8(10.4 \%)$ \\
\hline & & PDA & $7(9 \%)$ \\
\hline \multirow[t]{4}{*}{ CMP } & 75 (29.8\%) & PPCM & 57 (76\%) \\
\hline & & DCM & $11(14.7 \%)$ \\
\hline & & $\mathrm{HOCM}$ & $4(5.3 \%)$ \\
\hline & & Non-compaction & $3(4 \%)$ \\
\hline $\mathrm{PHT}$ & $10(4 \%)$ & & \\
\hline \multirow[t]{2}{*}{ IHD } & $4(1.6 \%)$ & & \\
\hline & 252 (100\%) & & \\
\hline
\end{tabular}

$A R$ aortic regurgitation, $A S$ aortic stenosis, $A S D$ atrial septal defect, $C H D$ congenital heart disease, CMP cardiomyopathy, DCM dilated cardiomyopathy, HOCM hypertrophic cardiomyopathy, IHD ischemic heart disease, MR mitral regurgitation, MS mitral stenosis, PDA patent ductus artriosus, $P H T$ pulmonary hypertension, $P H V$ prosthetic heart valve, $P P C M$ peripartum cardiomyopathy, PS pulmonary stenosis, TOF tetralogy of Fallot, VHD valvular heart disease, VSD ventricular septal defect or echocardiogram) to confirm the diagnosis. Patients were referred from in-hospital patients, outpatient clinic at the hospital, private clinics outside the hospital, or from other cities because of the complexity of cases that can not be managed and followed up in their cities. The study was performed in accordance with the ethical standards of the Declaration of Helsinki.

\section{Results}

According to the collected data (252 patients), among the main diagnosis of HD during pregnancy was valvular heart disease (VHD) 34.1\%, followed by congenital heart disease (CHD) 30.5\%, cardiomyopathy 29.8\%, pulmonary hypertension $4 \%$, and ischemic heart disease $1.6 \%$; (Table 1). Among subtypes of the main heart diseases in pregnant women, the most clinical pattern was: the prosthetic heart valve (26.7\%) in VHD (Fig. 1), both atrial septal defect and ventricular septal defect (35\%) in CHD, and peripartum cardiomyopathy (PPCM) (76\%) among cardiomyopathies.

\section{Discussion}

This study is showing the clinical pattern of HD in pregnancy among Iraqi patients at the first established cardio-maternal unit over the last 4 years, revealing that VHD as the main clinical pattern among pregnant patients and this is agreed with the current available and updated evidence that documented rheumatic VHD as the most common HD in pregnancy in emerging countries, which complicated $50-90 \%$ of $\mathrm{HD}$ in pregnancy and associated with the higher rate of mortality comparing with other $\operatorname{HD}[3,4,6,9-12]$.

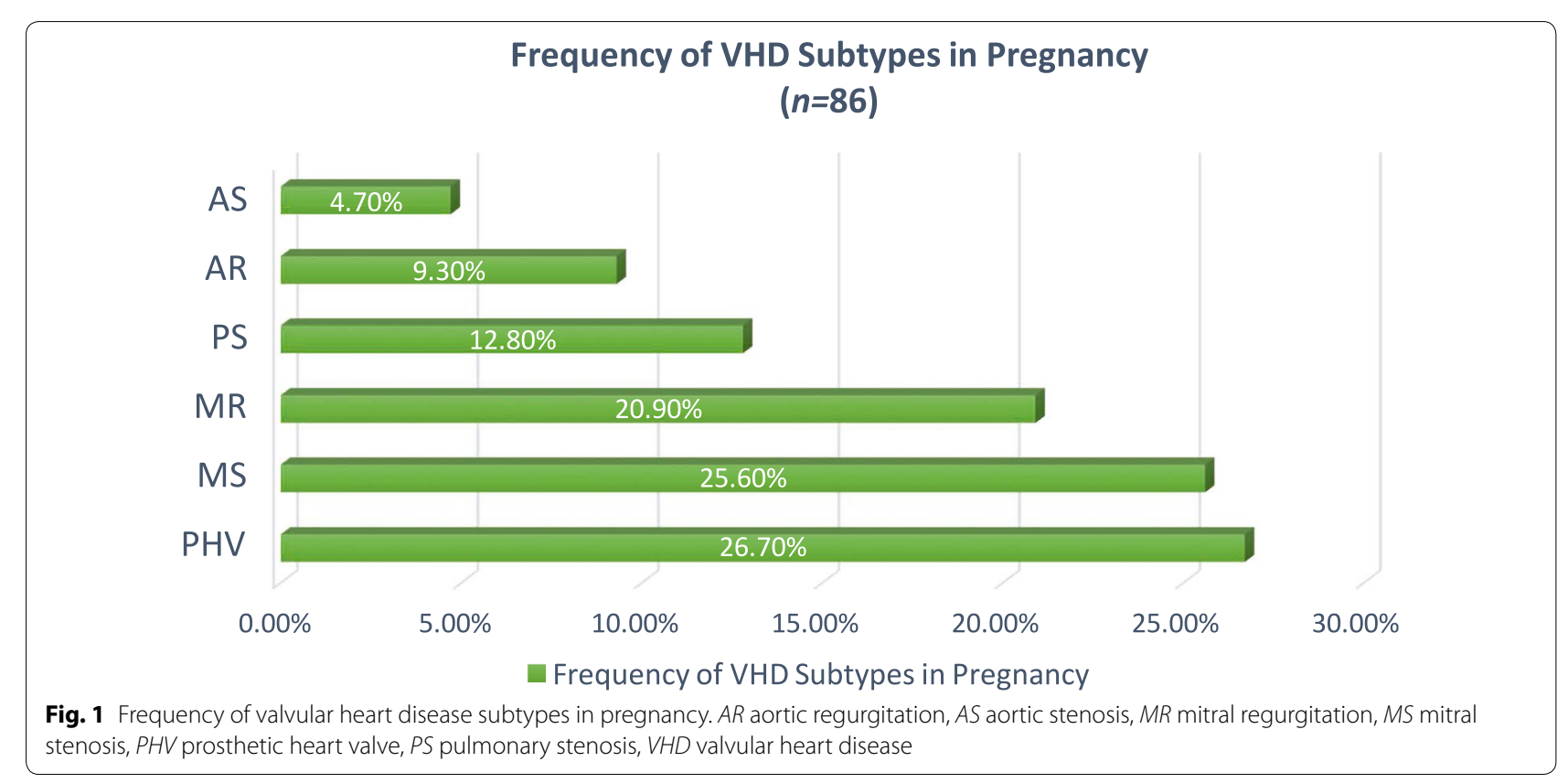


Prosthetic heart valve and mitral stenosis (MS) were predominate among pregnant women with VHD, and it is very important to focus on these subtypes of HD as prosthetic heart valve and MS are associated with high maternal and fetal complications, in addition, MS is considered as the most common leading cause for maternal mortality in patients with VHD in emerging countries especially postpartum mortality because it is poorly tolerated during pregnancy [3, 4, 9, 11-13]. Documentation the prevalence of VHD during pregnancy is essential to improve the standard of care of this condition especially in the emerging countries because despite the high burden of VHD particularly rheumatic heart disease (RHD) in these countries, still there is a limited data and studies on this topic, moreover, it will help in reducing the financial burden as the surgical intervention of RHD presents a high financial burden even in higher income countries [3, 13, 14]. For this reason, the World Heart Federation Working Group on rheumatic fever and RHD published a paper declaring a commitment to fight these diseases and to draw a detailed operational plan in order to control this burden of HD [12]. The second most prevalent $\mathrm{HD}$ in pregnancy was CHD. The prevalence of pregnant women with CHD is difficult to determine due to the methodology used in the reported studies [10]. The rate of deliveries of pregnant women with $\mathrm{CHD}$ rises by $34.9 \%$ over 10 -years period (1998-2007) which is explained by the advance diagnostic, medical and surgical management and care leading to improve the survival of more than $90 \%$ patients with CHD, reaching the reproductive age even those with more complex CHD [15-18]. However, pregnant women with CHD are more prone to develop cardiovascular and adverse obstetric and fetal complications, even the simple CHD can hold high pregnancy risk if their condition is associated with other comorbid disease $[15,17,18]$. Fortunately, most of these complications can be managed and the rate of mortality is rare $[10,16]$. Cardiomyopathy; mainly PPCM, followed VHD and CHD in this study. Incidence of PPCM varies depending on geographical regions [19]. It is a serious condition especially onemonth post diagnosis and associated with higher rate of major cardiovascular events reaching (46\%) comparing with dilated cardiomyopathy (39\%), therefore, requiring intensive and multidisciplinary management to improve outcomes $[5,20,21]$. In Summary, study and precise registration of pregnant women with HD is an important tool to improve the standard of care for those patients, reducing morbidity and mortality, and to reduce the health financial burden. Moreover, establishing a cardio-maternal unit with a multidisciplinary team is the cornerstone for optimizing care and management of HD in pregnancy.

\section{Conclusion}

This study showed for the first time the clinical pattern and prevalence of heart disease in pregnancy among Iraqi patients who were presenting to the first cardio-maternal unit in the country. The results demonstrated valvular heart disease as the main type of heart disease among the cohort patients followed by congenital heart disease and cardiomyopathy; particularly peripartum cardiomyopathy. Current data regarding heart disease during pregnancy is very limited, therefore, precise registration of such data is very essential for the future prevention and management of those patients and consequently to improve their outcomes by a multidisciplinary team in a specialized unit.

\section{Limitation}

Data include pregnant women with heart disease who were referred to our cardio-maternal unit does not reflect the real prevalence in our community.

\section{Abbreviations \\ CVD: cardiovascular disease; HD: heart disease; VHD: valvular heart disease; CHD: congenital heart disease; MS: mitral stenosis; RHD: rheumatic heart disease.}

\section{Acknowledgements}

We would like to thank the European Society of Cardiology/EurObservational Research Programme (ESC/EORP), the chairs of ROPAC (Prof. Jolien Roos-Hesselink and Prof Roger Hall), and the chairs of PPCM registry (Prof. Karen Sliwa and Prof. Johann Bauersachs) for using the CRF and protocol of ROPAC II and PPCM registry for collecting our data.

\section{Authors' contributions}

HAF designed the study, IFY analyzed and interpreted patient data. All the authors revised and approved the submitted manuscript and agreed to be personally accountable for the author's own contributions and to ensure that any related accuracy or integrity of any part of the work are appropriately investigated and resolved. Both authors read and approved the final manuscript.

\section{Authors' information}

H.A.F.: MD, PhD, FACC, FRCPE, FESC, FHFA, FICMS Cardiol, FSCAl, Professor and Consultant Cardiologist, is the President of Scientific Council of Cardiology at Iraqi Board for Medical Specializations. Head of Cardio-Maternal Unit at Baghdad Heart Center, Baghdad Teaching Hospital, Medical City.

I.F.Y.: BPharm, PhD, BCPS, FIBMS Clinical Pharmacy, MACCP, MACC, MESC, is a Clinical Pharmacy Specialist at Baghdad Heart Center, Baghdad Teaching Hospital, Medical City.

Funding

Not applicable.

\section{Availability of data and materials}

The datasets used and/or analyzed during the current study are available from the corresponding author on reasonable request. 
Ethics approval and consent to participate

The study was performed in accordance with the Declaration of Helsinki and was approved by the Scientific and Ethical Committee of Iraqi Board for Medical Specializations, and all participants signed a consent.

\section{Consent to publish}

Not applicable.

\section{Competing interests}

The authors declare that they have no competing interests.

\section{Author details}

${ }^{1}$ Scientific Council of Cardiology, Iraqi Board for Medical Specializations, Baghdad, Iraq. ${ }^{2}$ Baghdad Heart Center, Baghdad Teaching Hospital, Medical City, Baghdad, Iraq

Received: 13 July 2019 Accepted: 26 July 2019

Published online: 07 August 2019

\section{References}

1. van Hagen IM, Boersma E, Johnson MR, et al. Global cardiac risk assessment in the Registry Of Pregnancy And Cardiac disease: results of a registry from the European Society of Cardiology. Eur J Heart Fail. 2016;18:523-33.

2. Roos-Hesselink J, Baris L, Johnson M, et al. Pregnancy outcomes in women with cardiovascular disease: evolving trends over 10 years in the ESC Registry Of Pregnancy And Cardiac disease (ROPAC). Eur Heart J. 2019;00:1-8. https://doi.org/10.1093/eurheartj/ehz136.

3. Thorne S. Pregnancy and native heart valve disease. Heart. 2016;102:1410-7. https://doi.org/10.1136/heartjnl-2014-306729.

4. Nanna M, Stergiopoulos K. Pregnancy complicated by valvular heart disease: an update. J Am Heart Assoc. 2014;3:e000712. https://doi. org/10.1161/JAHA.113.000712.

5. Yaseen IF, Farhan HA. Registries for cardiac disease in pregnancy: an effective tool for organizing multidisciplinary team with better outcomes. J Am Coll Cardiol. 2018;71(11 Suppl):A2130. https://doi.org/10.1016/s0735 $-1097(18) 32671-8$.

6. Regitz-Zagrosek V, Roos-Hesselink JW, Bauersachs J, et al. 2018 ESC Guidelines for the management of cardiovascular diseases during pregnancy. Eur Heart J. 2018;39:3165-241. https://doi.org/10.1093/eurheartj/ehy340.

7. Gitt Anselm K, Bueno Hector, Danchin Nicolas, et al. The role of cardiac registries in evidence-based medicine. Eur Heart J. 2010;31:525-9. https:// doi.org/10.1093/eurheartj/ehp596.

8. Hammond E, Watts GF, Rubinstein Y, et al. Role of international registries in enhancing the care of familial hypercholesterolaemia. Int J Evid Based Healthc. 2013;11:134-9. https://doi.org/10.1111/1744-1609.12023.
9. Anthony J, Osman A, Sani MU. Valvular heart disease in pregnancy. CardiovasC J Afr. 2016;27:111-8. https://doi.org/10.5830/CVJA-2016-052.

10. Ashrafi R, Curtis SL. Heart disease and pregnancy. Cardiol Ther. 2017;6:157-73. https://doi.org/10.1007/s40119-017-0096-4.

11. Chhetri S, Shrestha NR, Pilgrim T. Pregnancy complicated by heart disease in Nepal. Heart Asia. 2014;6:26-9. https://doi.org/10.1136/heartasia-2013010396.

12. Remenyi B, Carapetis J, Wyber R, Taubert K, Mayosi BM. Position statement of the World Heart Federation on the prevention and control of rheumatic heart disease. Nat Rev Cardiol. 2013;10:284-92. https://doi. org/10.1038/nrcardio.2013.34.

13. van Hagen IM, Roos-Hesselink JW, Ruys TPE, et al. Pregnancy in women with a mechanical heart valve: data of the european society of cardiology registry of pregnancy and cardiac disease (ROPAC). Circulation. 2015;132:132-42. https://doi.org/10.1161/CIRCULATIONAHA.115.015242.

14. Seckeler MD, Hoke TR. The worldwide epidemiology of acute rheumatic fever and rheumatic heart disease. Clin Epidemiol. 2011;22(3):67-84. https://doi.org/10.2147/CLEP.S12977.

15. Schlichting LE, InsafTZ, Zaidi AN, Lui GK, Van Zutphen AR. Maternal comorbidities and complications of delivery in pregnant women with congenital heart disease. J Am Coll Cardiol. 2019;73:2181-91. https://doi. org/10.1016/j.jacc.2019.01.069.

16. Greutman M, Pieper PG. Pregnancy in women with congenital heart disease. Eur Heart J. 2015;36:2491-9. https://doi.org/10.1093/eurheartj/ ehv288.

17. Canobbio MM, Warnes CA, Aboulhosn J, et al. Management of pregnancy in patients with complex congenital heart disease: a scientific statement for healthcare professionals from the American Heart Association. Circulation. 2017;135:e50-87. https://doi.org/10.1161/CIR.0000000000000458.

18. Niwa K. Adult congenital heart disease with pregnancy. Korean Circ J. 2018:48(4):251-76. https://doi.org/10.4070/kcj.2018.0070.

19. Okeke TC, Ezenyeaku CCT, Ikeako LC. Peripartum cardiomyopathy. Ann Med Health Sci Res. 2013;3(3):313-9. https://doi.org/10.4103/21419248.117925

20. Sliwa K, Mebazaa A, Hilfiker-Kleiner D, et al. Clinical characteristics of patients from the worldwide registry on peripartum cardiomyopathy (PPCM). Eur J Heart Fail. 2017;19:1131-41. https://doi.org/10.1002/ ejhf.780.

21. Elkayam U, Goland S, Pieper PG, Silversides CK. High-risk cardiac disease in pregnancy. Part II. J Am Coll Cardiol. 2016;68:502-16. https://doi. org/10.1016/j.jacc.2016.05.050.

\section{Publisher's Note}

Springer Nature remains neutral with regard to jurisdictional claims in published maps and institutional affiliations.
Ready to submit your research? Choose BMC and benefit from:

- fast, convenient online submission

- thorough peer review by experienced researchers in your field

- rapid publication on acceptance

- support for research data, including large and complex data types

- gold Open Access which fosters wider collaboration and increased citations

- maximum visibility for your research: over 100M website views per year

At BMC, research is always in progress.

Learn more biomedcentral.com/submissions 